\section{THE DENTAL NEEDS OF THE ARMY.}

\section{To the Editor of THE LANOET.}

SIR,-Since I wrote my last letter I see that Sir J. D. Rees in Parliament has obtained from the Under Secretary for War a clear statement that there is no army dental corps and no need for one. I propose to give my reasons for believing that our army in France is in great need of a dental corps. When the medical history of this war is written two of the chief features will be the comparative absence of the epidemics which used to devastate armies and the prevalence of dental disorders. I attribute the improved general health of the army to the work of the medical service and the dental disorders to their neglect of the teeth. The attempt to do without a dental corps is as serious an error as saying that we have no Royal Army Medical Corps in France and there is no need for one.

And now let us examine how the War Office is trying to get the dental work done in France without a corps of their own. They are attempting to utilise the local practitioners, but it must be remembered that the French have already mobilised nearly every useful Frenchman, and one might as well try to form an English Royal Army Medical Corps out of what is left. In the second place, they have sent out a certain very limited number of dentists with the temporary rank of lieutenant. Perhaps it is the War Office alone who could tell us how few these men are, but they are certainly quite unable to deal with the present or coming requirements of the army. They are in about the same position in which a group of Royal Army Medical Corps lieutenants would be if sent over to France to attend our army and to do the work in their own sweet way under the control of a dental surgeon. Evidently something more is wanted, and it has been suggested that the medical officers should do the dental work. My belief is that they could undertake most of the extractions as we arranged in Rouen, but they have their hands full of their own work and need all the help they can get from the civilians, and certainly this is not the moment for them to go into training as dental specialists; still they can extract the soldiers' teeth.

There is, however, another little point to consider: Why do we never speak of our officers' teeth? Good dentistry may be a luxury for the soldiers, but it is a necessity for the officers, many of whom have been best part of a year in France already. A winter campaign seems probable. The nights will soon be getting cold, and large numbers of officers will suffer severely from neuralgia, as they did in the South African War. They will not all be within reach of a base, and even if they were I have already shown that the French dental surgeons are mobilised. England sleeps whilst other countries are moving. Canada leads the way with a special army dental service. France has already woke up. Germany is making in her army dental appointments that she has never made before. A very large English army is said to be coming to France, where insufficient arrangements are made for the care of the teeth both of officers and men, and it is to be hoped that the British lion will not be incapacitated with neuralgia just when he wanted to be in his best fighting trim.-I am, Sir, yours faithfully,

F. Newland-PedLey, F.R.C.S., L.D.S. Eng. Samois, France, July 23th, 1915.

\section{THE TREATMENT OF WOUNDS.}

\author{
To the Editor of THE LANCE't.
}

SiR,-The great divergence of opinion amongst surgeons and pathologists at the present time as to the best treatment of suppurating wounds is very unfortunate and discouraging. With so many wounded soldiers under our care, nearly all of whose wounds are suppurating, we are all of us seeking the best method of dealing with these septic wounds, and as yet there is no certain information. There does not seem to be any serious difference of opinion as to the urgent need for the thorough disinfection of gunshot wounds immediately after their infliction, but they are often such deep and tortuous tracks, blocked by protruding portions of torn muscle, that even if there were sufficient time the difficulty of disinfecting them would be great, though I think it is generally agreed that every possible means ought to be taken. But we are told by those at the front that unfortunately when there is a rush of wounded after any serious engagement there is no time thoroughly to deal with them, and the wounded may not arrive at any place where they can be adequately dealt with for a great many hours after the infliction of the wound. Hence practically all lacerated gunshot wounds which arrive in this country are freely suppurating, and within a few days of their infliction, before they come over, most serious complications sometimes arise. In fact, the surgery of the present war has taken us back to the pre-Listerian time which many of us can remember, only many of these gunshot wounds are much more terrible than the wounds we had then to deal with in civil life, and their profuse suppuration is therefore even more serious. But though a marked degree of hectic temperature is not rare in the bad cases, yet fortunately definite pyæmia and septicæmia do not seem common.

Will the use of a solution of hypochlorous acid, which Professor Lorrain Smith has shown ${ }^{1}$ to be the strongest antiseptic we possess, and capable of killing the spores of anthrax in a few minutes, in a strength which does no harm to the wound, make it more possible to disinfect these gunshot wounds? Even if the action of the antiseptic is hindered by the presence of the organic matter in the wound, if it will so quickly kill anthrax spores, which are so resistant to most antiseptics, may it not be able, perhaps in a somewhat stronger solution (but a solution even then probably non-injurious to the tissues), to kill the spores of those anaerobic organisms which so seriously infect some gunshot wounds? And if it cannot do this, may it not kill all the more common pyogenic organisms, even after many hours from the infliction of the wound ? And may not the application of the hypochlorous acid gas generating pad, as a first dressing, do, at any rate, something to inhibit the growth of organisms until the wound can be thoroughly disinfected? But the difficulty in the use of gases, and ointments, and powders is that they do not really penetrate into the depth of a deep and tortuous track.

But it is with regard to the treatment of already suppurating wounds that there is such a serious divergence of opinion. We are told by Sir Almroth Wright ${ }^{2}$ that it is useless to apply an antiseptic to a suppurating wound, as it cannot penetrate the living granulation tissue or the leucocytes, and

\footnotetext{
Brit. Med. Jour., July 24th, 1915, p. 405. 2 The Lancet, April 24 th, p. 843 .
} 
that if it did penetrate the granulation tissue it would be absorbed by the blood or washed out by the lymph; and, moreover, we are also told it may do harm by paralysing the phagocytic action of the leucocytes. He advises us to use not antiseptics, but saline solutions of a certain strength, which will encourage the outflow of lymph and so bring active phagocytes to destroy the organisms. On the other hand, Sir Watson Cheyne tells us ${ }^{3}$ that he considers Sir Almath Wright over-estimates the value of lymph as a bactericide, and does not recommend the use of this strong saline solution. But he is very strongly of opinion that antiseptics do harm in suppurating wounds, because they interfere with the antibacterial action of the tissues, and he quite agrees with Sir Almroth Wright in his view that they have no power to deal with organisms which have already penetrated into the tissues around the wound-the wall of the wound.

The very remarkable series of experiments of Mr. C. J. Bond ${ }^{4}$ have shown that quite strong antiseptics do not interfere with the healing of a recent operation wound, and therefore that there is no ground for the terrible fear of the entrance of antiseptics into wounds at operation which many surgeons suffer from. But it also makes one sceptical as to whether, after all, antiseptics really do such damage to the living tissues and cells as to interfere with their antibacterial action in suppurating wounds. In THE LANCET of July $24 \mathrm{th}, \mathrm{p}$. 165 , is a paper by Dr. Paul Fildes and others strongly advocating the treatment of suppurating wounds by a very powerful antiseptic solution, and instead of injuring the granulation tissue we are told that it becomes remarkably healthy and the wounds heal well. Whether suppurating wounds would really do better treated with this strong antiseptic, or simply washed out with saline solution of the strength recommended by Sir Almroth Wright, or with normal saline solution, must, I think, be doubtful. It would require very careful and extensive observation to determine, but it is evident from the experience published by Dr. Fildes that a strong antiseptic does no more harm in a suppurating wound than, as has recently been shown, it does in a recent aseptic one. I have been treating cases of profusely suppurating gunshot wounds-many of them compound fractures-by syringing them out, or by continuous irrigation with Wright's saline solution, and most of them have done very well; but I have not made an extensive or systematic trial of Wright's method, and cannot, therefore, publish any reliable results. We all, of course, carry out what Sir Almroth Wright so strongly advocated-the freest possible drainage and washing out of the pus, and, if needful, continuous irrigation, but this cannot be considered as Wright's method, as it has been one of the primary principles of surgery for many years. In the British Medical Journal, also for July 24th, p. 129 , is another paper by Professor Lorrain Smith and other pathologists at Edinburgh strongly recommending the use of hypochlorous acid for septic wounds. They claim that the purulent discharge becomes serous and that the wounds "clean" and heal well. Evidently here again no harm is done by the introduction of a strong antiseptic into a suppurating wound.

There is one statement made by Sir Almroth Wright which seems to me remarkable. ${ }^{5}$ He says

3 The Lancer, Mav 8th, p. 961 ; and Brit. Med. Jour., 1914, vol. ii., p. 870 . 4 Brit. Med. Jour., 1915, vol. i., p. 405 that although he does not consider antiseptics do any good to the wound to which they are applied, yet their application does good inasmuch as it pre. vents the transference of organisms from one wound to another. But surely it is not desirable to apply antiseptics to a wound for this purpose, nor can we expect a weak antiseptic applied to the wound for a few minutes to act as an efficient bactericide and prevent such transference. All instruments should be boiled between the dressings, all swabs discarded, fresh lotion used, and if gloves are not changed, at any rate the gloved hands should be thoroughly washed.

Although Dr. Fildes and the other authors of the paper in THE LANCET say that they have arrived at a somewhat different conclusion from that of Sir Almroth Wright, yet they state, with regard to his recent address on wound treatment, that there are few passages in the paper to which they are disposed to take exception. It seems to me that their treatment of suppurating wounds is entirely different both in theory and practice to that of Sir Almroth Wright's. He asks (p. 845), "how is it that the obvious non-success of the antiseptic treatment is not generally appreciated." The authors of this paper advocate such treatment and show that in some wounds at any rate it is successful. It is true that though in Sir Almroth Wright's address at the Royal Society of Medicine, from which the above quotation is taken, he tried to prove that not antiseptic, but " physiological," methods were the right treatment for suppurating wounds, yet in a joint communication on the subject (page 876 of the same number of THE LANCET) he considers the possibility that an antiseptic may be some use in a suppurating wound, and thus seems to be less confident in his opinion, yet he sums up the observation by saying ..... "up to the present, experiment has not furnished anything in confirmation of the idea that the introduction of an antiseptic into wounds would be likely to contribute to the arrest of suppuration.'

I cannot understand the reasons for the opinion of Dr. Fildes and the other authors of the paper that "an antiseptic as a primary method of treatment must fail." By "primary method" they must obviously mean at the time of the injury. They say it is useless to expect an antiseptic applied to the superficial aspect of a wound to disinfect the deep part. This is, of course, obvious. But why should not the antiseptic be applied to the deep part also? If some time is spent over the attempt, and, if necessary, an anæsthetic given, and the tracks opened up, a powerful antiseptic may be injected into all its recesses. Extensive compound fractures, with great laceration of surrounding tissue, in civil practice may be sterilised in this way. I was greatly surprised when some months ago I read Sir Almroth Wright's reason for thinking it was im. possible to sterilise recent gunshot wounds. ${ }^{6} \mathrm{He}$ says that in the ordinary compound fracture of civil life microbes lie exposed on the extruded surface of the bone, which has been thrust through the skin and so can be readily killed, but that this condition is very different from a gunshot wound in which they are buried deeply in the tissues. But Sir Almroth Wright seems to have no conception of the ordinary compound fracture of civil life. The bone does not often protrude through the skin when the case comes before the surgeon for treatment, and whether it does or does not, there is often an extensive deep lacerated wound, and the

\footnotetext{
6 Ibid., p. 843.
} 
disinfection of this may demand much care and thoroughness, and yet such a wound may be quite successfully sterilised by a strong antiseptic.

I am Sir, yours faithfully,

Bristol, July 25th, 1915.

Charles A. Morton.

PS.-As will be seen from the date of this letter, it was sent to the Editor of THE LANCET before Sir Watson Cheyne's paper, and the leading article on the same subject, appeared in THE LANCET of July 31st. I very greatly regret to find I was wrong in thinking there was a general agreement that a most thorough attempt should be made to disinfect all these lacerated gunshot wounds at the earliest possible moment. I recognised, as I say in the letter, that the case might not arrive at a clearing station in time, or the rush then might be too great, for the successful disinfection of all the wounds, but I imagined every endeavour was made to do this. I thought that those who were not convinced that this was the best thing to do before reading Sir Watson Cheyne's remarks on the subject in his address at the Medical Society last autumn, and since, were now convinced. Perhaps the encouraging experience of Mr. Edmunds in the Dardanelles may lead to the more general adoption of the practice. July 31st.

\section{THE RECOGNISED PLACES OF CLINICAL STUDY. \\ To the Editor of THE LANCET.}

SIR,-I am directed to forward you the enclosed copies of correspondence, with a request that you will be pleased to publish them in your columns. The first letter is one addressed to the three examining boards in London; the replies to that letter follow.

The request made by the West London Hospital appears to be reasonable and of urgent necessity in these days of war emergency. One examining board recognises this emergency and grants the request; the other two refuse it, and, perhaps wisely, state no reason for their refusal. Emergency has cut much red tape of late; even trade union rules have gone. But our examining boards still "bind heavy burdens and grievous to be borne, and lay them on men's shoulders, but they themselves will not move them with one of their fingers."-I am, Sir, yours faithfully,

N. Bishop HaRMaN,

July 20th, 1915. Vice-Dean, Post-Graduate College, West London Hospital, Hammersmith.

[ENCLOSURES.]

Post-Graduate College, West London Hospital, Hammersmith, June 19th, 1915.

DEAR SIR, 一Owing to the necessity for releasing medical men of military age there is increasing diffeculty in obtaining the necessary skilled assistance for the satisfactory working of general hospitals. The difficulty has been acutely felt at the West London Hospital. At the present time we are able in some degree to meet it by obtaining the assistance of senior students who are as yet unqualified, who work under the direction of the resident medical officers as dressers for surgical cases. These men are paid for the work and found in board and lodging. To make this work really suitable for them without delaying the date at which they would ordinarily be able to proceed to their final examinations, $\mathrm{I}$ am authorised to make application to you for the official recognition of this hospital as a place of clinical study for men who have passed their intermediate examination. The hospital is at present recognised as a place of study for post-graduates and for men reading for higher professional qualifications. There is ample clinical material of all kinds, and full facility for personal teaching by the staff, both resident and visiting. We have at the moment two men acting as dressers in the surgical wards, and I shall be glad if your council will be pleased to grant the request made in this letter, that you will make it retrospective so as to apply to these two men. The application for this recognition is for the duration of the war only.

I am, yours faithfully,

(Signed) N. Bishop Harman, Vice-Dean.

Fxamination Hall, 8-11, Queen-square, Bloomsbury, London, W.C., June 24th, 1915

DEAR SIR, - I have submitted your letter of the 19th instant to the Committee of Management of this Board, and I am desired to inform you that they do not see their way to comply with your request.

I am, dear Sir, yours faithfully, (Signed) F. G. HaLlett, Secretary.

N. Bishop Harman, Esq., F.R.C.S.

University of London, South Kensington, London, S.W., July 15th, 1915 .

DEAR SIR,-I regret to inform you that, after consideration of your letter of June 19th last, making application for the temporary recognition of the West London Hospital for clinical study for the purposes of the M.B., B.S. examination, and of reports thereon from the relevant Committees of the Senate, it was resolved by the Senate at their meeting on 14th July, 1915, that the application be not acceded to. I am, dear Sir, yours faithfully, (Signed) P.J. HartoG. Academic Registrar. The Vice-Dean, Post-Graduate College, West London Hospital, Hammersmith, $W$. Society of Apothecaries of London, Blackfriars, London, E.C.,
June 24th, 1915.

DEAR SIR, - I am requested to inform you that the Court of Examiners are willing to recognise work done at the West London Hospital for clinical teaching during the war "for students who have passed their examination in Anatomy and Physiology."

Would you be good enough to send me the names of the two students who are acting as dressers? Yours faithfully,

(Signed) Frank HAYDon, Secretary.

N. Bishop Harman, Esq., M.B., F.R.C.S.,

West London Hospital, $W$.

We have every sympathy with the desire of the authorities of the West London Hospital to secure for the senior students working at the institution under the direction of the resident medical officers the fullest recognition of their time so spent, but we cannot say that we are surprised to find that the English Conjoint Board and the University of London were unable to accede to the request made to them. There are two sides to the question and the Society of Apothecaries saw one. But at the present time there is no demand for additional centres of clinical instruction for medical students. The hospitals attached to medical schools being short of their usual complement give ample opportunities for those left behind to obtain clinical appointments without losing the benefit of classes of instruction which can be conveniently given in the medical schools.-ED. L.

\section{THE RECENT OUTBREAK OF BUBONIC PLAGUE IN CUBA. \\ To the Editor of THE LANCET.}

SIR,-The present reappearance of plague in Havana commenced on Feb. 5th last. The sanitary authorities of Cuba believe this to be a recrudescence of the outbreak of 1912, which appeared to have been extinguished by June 20th, 1914. There is every reason to believe that their supposition is correct. Three cases occurred in February, one in March, eight in April, and four in May up to the $7 \mathrm{th}$ of that month, making a total of 16 cases in all. No case has developed between May 7th and the present date-May 25th. Dr. J. Guiteras, the director of health, called attention to the fact that the first cases in this recent outbreak occurred in a circle around the zone which had been rat-proofed the previous year. The cases have been mostly confined to wholesale groceries and forage stores in 